\title{
Anesthetic Consideration for Neurointerventional Procedures
}

\author{
Kyung Woon Joung, MD², Ku Hyun Yang, MD', Won Jung Shin², Myung Hee Song, MD², \\ Kyungdon Ham, MD², Seung Chul Jung, MD', Deok Hee Lee, MD', Dae Chul Suh, MD'
}

Interventional neuroradiology (INR) has been a rapidly expanding and advancing clinical area during the past few decades. As the complexity and diversity of INR procedures increases, the demand for anesthesia also increases. Anesthesia for interventional neuroradiology is a challenge for the anesthesiologist due to the unfamiliar working environment which the anesthesiologist must consider, as well as the unique neuro-interventional components. This review provides an overview of the anesthetic options and specific consideration of the anesthesia requirements for each procedure. We also introduce the anesthetic management for interventional neuroradiology performed in our medical institution.

Key Words : Anesthesia; Interventional neuroradiology; Neurointervention

Anesthesiological patient management in interventional neuroradiology (INR) is a challenge for the anesthesiologist as the working environment differs from that of the surgical suites [1-3]. In most medical centers, the room used for neurointerventional procedures is usually distant and separate from the surgical suites and is equipped with a specifically designed lighting apparatus for the complicated angiography units. Therefore, anesthesiologists who perform anesthesiological patient management for INR procedures should always be aware of the flow of human traffic related to intravenous (IV) and airway

\footnotetext{
'Department of Radiology and Research Institute of Radiology, ${ }^{2}$ Department of Anesthesiology and Pain Medicine, University of Ulsan, College of Medicine, Asan Medical Center, Seoul, Korea

Received August 14, 2014; accepted after revision August 23, 2014. Correspondence to: Dae Chul Suh, MD, Department of Radiology, Asan Medical Center, University of Ulsan, College of Medicine, 86 Asanbyeongwon-gil, Songpa-gu, Seoul 138-736, Korea.

Tel. 82.2.3010.4366 Fax. 82.2.476.0090

E-mail: dcsuh@amc.seoul.kr

This is an Open Access article distributed under the terms of the Creative Commons Attribution Non-Commercial License (http://creativecommons.org/licenses/by-nc/3.0) which permits unrestricted non-commercial use, distribution, and reproduction in any medium, provided the original work is properly cited.
}

access, as they are unaccustomed to these procedures and also to the neuroangiosuites.

General anesthetic considerations for the INR procedure are maintaining neuromuscular relaxation for good image quality, rapid and smooth recovery for immediate post-procedural neurologic examination, maintaining anti-coagulation, managing sudden complications, and radiation hazards. For the most part, preoperative evaluations of the INR procedure do not differ from those of other procedures or surgery. Evaluation of the airway, baseline blood pressure, cardiovascular reserve, respiratory reserve, and other comorbidities are important. In addition, pre-existing neurologic conditions, such as any deficits present, the Glasgow Coma Score, and whether there is a rise of intracranial pressure, are also important. For some special aspects, more careful evaluation of the preoperative coagulation profile is mandatory as many patients are medicated with anti-coagulants during the preoperative period and most INR procedures require anticoagulation. Moreover, any unpleasant experiences during previous angiography procedures are also evaluated in detail in order to detect any possible allergy to the contrast agent or other medication, such as protamine sulfate. We present the anethesiological 


\section{Anesthetic Consideration for Neurointerventional Procedures}

principle, procedures, and specific management for each of the cerebrovascular diseases based on the current neuro-interventional procedures performed at Asan Medical Center in Seoul, Korea.

\section{Selection of the anesthesiological mode}

There is no clear conclusion concerning which mode of anesthesiology is superior to another. Procedural complexity as well as the length of the procedure, degree of immobilization, patient status, and satisfaction of the interventionist should be considered for selection of the anesthesiological mode. We describe the current trend and the mode of general anesthesia which is most commonly used as well as monitored anesthesia care (MAC) by which neuro-interventional procedures can be performed during a patient's conscious state.

\section{General anesthesia}

Most INR procedures are performed under general anesthesia, as it provides greater patient safety and better image quality due to patient immobilization. Patients are less anxious and more comfortable than with MAC under unconsciousness. Moreover, general anesthesia is helpful in order to maintain intracranial pressure (ICP), because controlled ventilation provides normocapnia or mild hypocapnia. On the other hand, a disadvantage of general anesthesia is that neurological assessment is not available during the intra-operative period. An increase of ICP or blood pressure at the time of endotracheal intubation and extubation is another disadvantage of general anesthesia. Short-acting narcotics, such as remifentanil or fentanyl, or a short-acting beta-blocker may be helpful in controlling this problem. Selection of the specific anesthetic agent for general anesthesia is generally considered based on the patient's comorbidities. We recommend total intravenous anesthesia or a combination of intravenous remifentanil and a volatile agent, which may be helpful in leading to rapid induction or arousal as well as maintaining patient stability during the procedure. Continuous infusion of a muscle relaxant may improve the image quality as it can prevent intermittent movement, intra-operatively. As continuous infusion of a muscle relaxant brings about a profound blockade and a prolonged recovery time, Sugammadex, the first selective relaxant binding agent, has been recently introduced as a new reversal agent that selectively and directively binds relaxants blocked by rocuronium or vecuronium. The greatest advantage of this agent is that it can reverse any depth of neuromuscular block by 1:1 binding of rocuronium or vecuronium [4]. In our medical institution, all of the patients who undergo INR procedures under general anesthesia receive continuous infusion of rocuronium in order to maintain their full relaxation, which is reversed by Sugammadex at the end of procedure.

\section{Conscious sedation}

According to the American Society of Anesthesiologists (ASA), MAC is a planned procedure during which the patient undergoes local anesthesia together with sedation and analgesia. The most beneficial effect of MAC is that neurologic examination is available at any time during the INR procedure without hemodynamic instability. However, most sedative drugs have the potential for upper airway obstruction and respiratory depression. Therefore, anesthesiologists should always consider the possibility of converting MAC to the other type of anesthesia.

The patient's pain, anxiety and discomfort, respiratory and cardiac effect, and the recovery profile of anesthetic drugs should be considered when an anesthetic agent for MAC is chosen. Propofol is widely used in various procedures that require sedation because it demonstrates a fast onset, short half-life, and rapid recovery $[5,6]$. Despite these advantages, Propofol has a critical drawback, as it may induce severe respiratory depression, even apnea.

On the other hand, the highly selective alpha-2 agonist, Dexmedetomidine (Precedex ${ }^{\circledR}$ ) demonstrates both analgesic and hypnotic properties and with little effect on respiration. Moreover, Dexmedetomidine reduces stress responses to surgery by reducing the sympathetic tone, so that Dexmedetomidine can be selectively used for INR procedures for which general anesthesia is not definitely required.

\section{Principle of cerebral perfusion}

The normal cerebral blood flow (CBF) is approximately $50 \mathrm{ml} / 100 \mathrm{~g} / \mathrm{min}$ or $700 \mathrm{ml} / \mathrm{min}$, which is roughly $14 \%$ of the cardiac output, and CBF ranges from $20 \mathrm{ml} / 100 \mathrm{~g} / \mathrm{min}$ in white matter to $70 \mathrm{ml} / 100$ $\mathrm{g} / \mathrm{min}$ in grey matter [5-7]. CBF can be measured using the following equation:

$$
\begin{aligned}
\mathrm{CBF}= & \text { Cerebral Perfusion Pressure }(\mathrm{CPP}) / \\
& \text { Cerebrovascular resistance }(\mathrm{CVR}) \\
\mathrm{CPP}= & \mathrm{MAP}-\mathrm{ICP}
\end{aligned}
$$




\section{Kyung Woon Joung, et al.}

CPP is defined as the difference between mean arterial pressure (MAP) and intracranial pressure (ICP). MAP is the diastolic pressure plus one-third of the pulse pressure. It differs from the mean value between the systolic and the diastolic pressure. When maintaining constant and stable ICP without an increase, CPP is directly matched with MAP. Pressure autoregulation maintains $\mathrm{CBF}$ at a constant level in the normal brain, with the exception of the usual fluctuations in blood pressure between MAP $50 \mathrm{mmHg}$ and $150 \mathrm{mmHg}$ [8, 9]. However, above or below the normal pressure, CBF will become pressure-dependent. For the traumatic or ischemic brain which has destroyed pressure autoregulation, $\mathrm{CBF}$ may become blood-pressure dependent in entire MAP ranges (Fig. 1).

$\mathrm{CBF}$ is also influenced by CVR. CVR is controlled by the metabolic factor (cerebral metabolic rate for oxygen, $\mathrm{CMRO}_{2}=3.5 \mathrm{ml} / 100 \mathrm{~g} / \mathrm{min}$ ), chemical factors $\left(\mathrm{O}_{2}\right.$ and $\mathrm{CO}_{2}$ tensions), body temperature, the nervous system, etc. Regional CBF is tightly coupled to brain metabolism. Energy metabolites cause local cerebral vasodilatation, thus assisting the rapid regional control of CBF. As the $\mathrm{CMRO}_{2}$ increases, there is a parallel increase in $\mathrm{CBF}[5,6,10]$.

Carbon dioxide can have a significant influence on CBF. As the $\mathrm{PaCO}_{2}$ rises, vasodilatation increases CBF and when $\mathrm{PaCO}_{2}$ is reduced, vasoconstriction occurs. Within the physiological range of 20 to $60 \mathrm{mmHg}, \mathrm{CBF}$ changes linearly by $3 \%$ to $4 \%$ per $1-\mathrm{mm} \mathrm{Hg}$ change in $\mathrm{PaCO}_{2}$. When $\mathrm{PaCO}_{2}$ is less than approximately $20-\mathrm{mm}$ $\mathrm{Hg}$, there is no further reduction in CBF. Therefore, there is no advantage in inducing further hypocapnia as this will only shift the oxygen dissociation curve further to the left, and thus making oxygen less

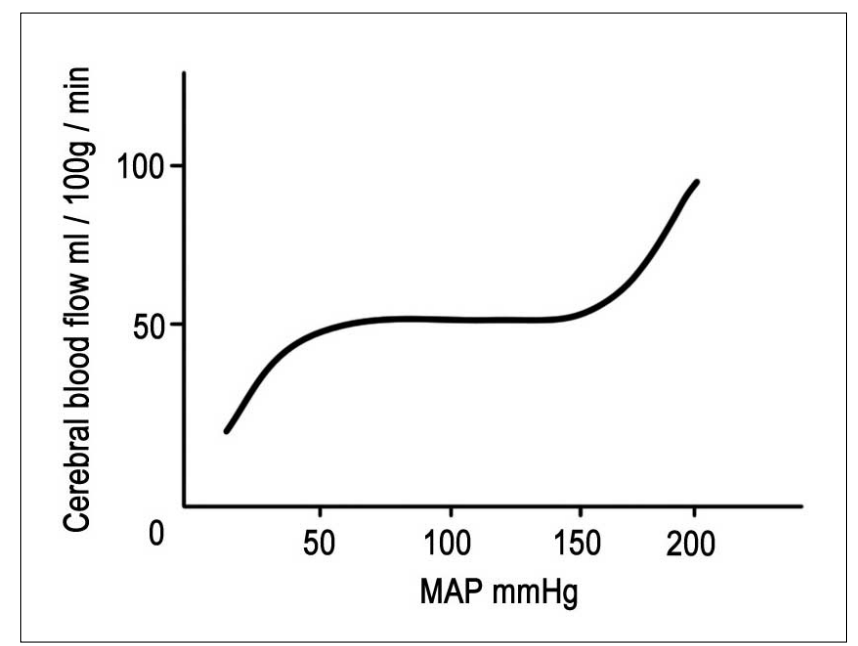

Fig. 1. Autoregulation of cerebral blood flow. available to the brain tissue (Fig. 2).

As acute hyperventilation causes a reduction of $\mathrm{PaCO}_{2}$, it can decrease the ICP. However, excessive hyperventilation may cause iatrogenic ischemia. A prolonged change in systemic $\mathrm{CO}_{2}$ tension is accompanied by active transport of bicarbonate in or out of the cerebrospinal fluid in order to restore a normal, acidbased balance. Therefore, the effects of hyperventilation on the CBF are not sustained beyond 24 hours. Another goal of acute hyperventilation is to constrict normal cerebral vessels and to redistribute blood to maximally dilated vessels in an ischemic area of the brain [5, 6, 11]. This is the so-called Robin Hood effect. Arterial $\mathrm{PO}_{2}$ has a minimal effect until $\mathrm{PO}_{2}$ drops below $50 \mathrm{mmHg}$, when $\mathrm{CBF}$ increases significantly (Fig. 2).

Patients with neurovascular diseases may have one or more impaired homeostatic mechanisms. Consequently, cerebral metabolism is depressed in patients with an altered level of consciousness, ICP may be elevated, flow-metabolism coupling may be lost, autoregulation may be impaired, and the blood-brain barrier may be disrupted. Except in patients who are severely injured, the $\mathrm{CO}_{2}$ reactivity is usually preserved. Even preoperatively, their mean arterial pressure and ICP may need to be carefully controlled in order to maintain adequate $\mathrm{CBF}$.

Anesthetic techniques may also affect the cerebral physiology. Intravenous anesthetic agents, including thiopental and propofol, are indirect cerebral vasoconstrictors which may reduce cerebral metabolism coupled with a corresponding reduction in CBF [12]. The cerebral effects of inhaled anesthetics are twofold, i.e. they are intrinsic cerebral vasodilators, although

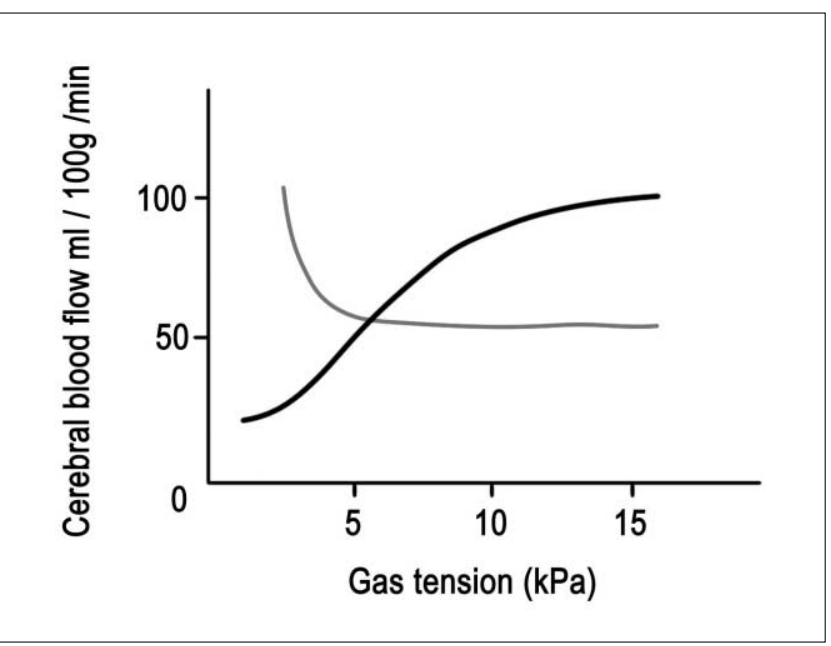

Fig. 2. Effects of chemical factors on cerebral blood flow $(1 \mathrm{kPa}=$ $7.51 \mathrm{mmHg}, \mathrm{pCO}_{2}=$ thick line, $\mathrm{pO}_{2}=$ thin line). 
their vasodilatory actions are partly opposed by flowmetabolism coupling mediated vasoconstriction secondary to a reduction in CMR. The overall effect is unchanged $\mathrm{CBF}$ during low-dose, inhaled anesthesia, but increased CBF during high doses. With the exception of sevoflurane which appears to preserve autoregulation at all clinically relevant doses, other inhaled agents impair autoregulation in a dosedependent manner [13]. Muscle relaxants generally have negligible or clinically insignificant effects on ICP, although tracheal intubation, itself, may cause intracranial hypertension which may be attenuated by pretreatment with lidocaine, opioids or both [14].

\section{Arterial line placement}

The radial artery is usually preferred for securing arterial blood and for cannulation to provide continuous blood-pressure monitoring and arterial-blood sampling. Because a femoral arterial sheath can sometimes provide room for the arterial line, agreement of the anesthesiologist and the interventionist can avoid routine, arterial-line cannulation, which sometimes causes a bleeding problem in the wrist, even though the rate is very low.

If the radial artery cannot be cannulated, the femoral artery offers an alternative. Arterial line placement can be performed using multiple methods, which are determined by puncture location, operator preference, and available equipment. The arterial line monitoring is maintained for one or two days until the patient's vital signs become stabilized.

\section{Coil embolization of a cerebral aneurysm}

The life-long incidence of intracranial aneurysm is $1.5-8.0 \%$, and multiple aneurysms occur in $20 \%$ of these people [15]. Neurosurgical clipping and endovascular coil embolization are representative treatments of intracranial aneurysms in Korea [2]. Since the International Subarachnoid Aneurysm Trial (ISAT) reported that coil embolization showed better one-year and seven-year survival rates than neurosurgical clipping in ruptured intracranial aneurysms [16], many institutions perform endovascular-coil embolization as the first-choice therapy for an intracranial aneurysm.

The anesthetic goal for the unruptured aneurysm patient is to prevent aneurysm rupture. Because acute elevation of blood pressure may cause an aneurysm rupture, all patients need careful monitoring of possibly invasive atrial blood pressure. We recommend maintaining the systolic blood pressure below 120 $\mathrm{mmHg}$. If a patient's blood pressure is high, a shortacting beta-blocker (labetalol $10 \mathrm{mg}$ IV) or a calcium channel blocker (nicardipine 1-2 mg IV) may be helpful.

Common and fatal complications of aneurysm rupture are re-bleeding and vasospasm. Re-bleeding is the most common cause of death for patients hospitalized after subarachnoid hemorrhage (SAH) [17]. To prevent re-bleeding, early intervention and prevention of blood pressure surge are important. Vasospasm associated with the presence of blood in the basal cisterns may lead to cerebral ischemia. If vasospasm is detected, the anesthesiologist should carefully control the patient's blood pressure in order to maintain cerebral perfusion pressure by application of $\mathrm{HHH}$ therapy (hypertension, hypervolemia, hemodilution).

\section{Arteriovenous malformations}

Arteriovenous malformations (AVM) are a large, complex, vascular architecture, called the nidus, which consists of feeding arteries, fistula, and draining veins. Patients with AVMs usually present with one or more symptoms, including headache, seizure, mass effect, nausea, vomiting, diplopia, or hemorrhage. Embolization of an AVM is performed in order to obliterate the AVM nidus or reduce the size of the nidus before surgical or radiological resectioning.

Hyperventilation may be helpful for redistribution of blood flow: it causes a reduction of blood flow in normal brain parenchyma while maintaining the blood flow in an AVM nidus that is the target of the embolization $[5,11]$. The cyanoacrylate glues most frequently use "closure" of abnormal vessels as they are lowviscosity, liquid monomers and polymerize by binding of the ionic solution of blood. The most serious complication of liquid embolic agent injection is acute cerebral hemorrhage which is caused by passage of liguid embolic agent to the drainage vein. In this context, mild hypotension during the procedure may be helpful. Onyx is a new, non-adhesive, liquid material which has shown a higher initial complete obliteration rate than other embolic agents $[18,19]$. Because the onyx is more adhesive than the glue, it is less influenced by blood pressure.

\section{Carotid angioplasty and stenting}

Carotid angioplasty and stenting (CAS) is an alternative treatment used to prevent cerebral infarction in 
high-risk patients [20]. Carotid Revascularization Endarterectomy versus Stenting Trial (CREST) showed no significant overall difference between the stenting and the endarterectomy groups in the rates of a composite outcome that included major periprocedural complications, such as stroke, myocardial infarction or death, and ipsilateral stroke over a four-year, follow-up period [21]. According to the CREST results, the American College of Cardiology (ACC)/American Heart Association (AHA) recommended CAS as an alternative to CEA for symptomatic carotid stenosis [22].

The anesthetic technique for CAS is often performed under MAC. General anesthesia is not prefered because neurologic function cannot then be evaluated during the CAS procedure. During CAS, severe bradycardia or asystole may occur due to stretching of the carotid body [23-25]. Anesthesiologists should be cautioned regarding this unpredictable reflex. If severe bradycardia or asystole occurs in intra-operative period, IV atropine $(0.5-1 \mathrm{mg})$ or glycopyrrolate $(1 \mathrm{mg})$ can be administered. Cerebral hyperperfusion syndrome (CHS) is characterized by ipsilateral headache, hypertension, seizure, and focal neurologic deficit. CHS often occurs in patients with an increase of more than $100 \%$ in cerebral perfusion following the procedure, compared with the baseline [26]. As perfusion is pressure-dependent in patients with $\mathrm{CHS}$, strict blood-pressure control is recommended. We recommend to maintain the systolic blood pressure below $120 \mathrm{mmHg}$ and also to adjust the systolic pressure about $80 \%$ of the pre-operative systolic pressure. To control the blood pressure, direct vasodilators, such as calcium channel blocker, nitroprusside, and glyceryl trinitrate, are not recommended as these drugs induce cerebral vasodilation and increase cerebral perfusion $[8,27,28]$. Beta-blockers can be used according to the cardiac status.

\section{Acute stroke}

In acute ischemic stroke, it is possible to recanalize the occluded vessel by mechanical thrombectomy or intra-arterial chemical thrombolysis. Though these procedures have an inherent risk for promoting hemorrhagic transformation, the management of acute cerebral stroke requires MAP to be maintained at supranormal levels because of inadequate collateral perfusion secondary to the acute arterial infarction. The risk for vessel rupture or clot propogation is omnipresent.

\section{Postoperative care}

All patients who have undergone an INR procedure should be intensely monitored during the immediate, post-procedural period. Maintenance of blood pressure depends on each procedure; slightly low blood pressure is maintained after CAS and AVM embolization and hypertension is maintained after coil embolization for ruptured aneurysms. Neurologic examination should be performed repeatedly during the post-procedural period, and CT or other imaging study is required if any neurologic deficit is detected.

Contrast-induced nephropathy is another problem presenting during the post-procedural period. This is one of the common causes of hospital-acquired, renal failure, of which the incidence is approximately $5 \%$ [29]. Because it is not yet known whether there is any definitive treatments of contrast-induced nephropathy or not, risk management and prevention are important. The risk factors of contrast-induced nephropathy include hypotension, congestive heart failure, old age ( $>75$ years), anemia, diabetes, contrast-media volume, and application of an intra-aortic balloon pump [30]. In order to prevent contrast-induced nephropathy, adequate hydration is necessary during the INR procedure. Current meta-analysis has reported that $\mathrm{N}$ acetylcysteine or theophylline is also helpful in order to prevent contrast-induced nephropathy [31, 32].

\section{Conclusion}

Increasingly complex neurointerventional procedures will continue to challenge anesthesiologists. An understanding of the current and future developments in this field is important. Although the general principles governing intracranial hemodynamics and function are similar, patients undergoing different neurointerventional procedures for different pathologic conditions may require much different types of anesthesia and monitoring care. Successful intraoperative management of these challenging patients requires a basic understanding of the pathophysiology and neuro-interventional demands of the procedure, all of which start with a thorough preoperative evaluation and preparation of the patient.

\section{References}

1. Zhao LB, Miyachi S, Shi HB, Suh DC. Comparison of medical education and requirements for training in the interventional neuroradiology in china, Japan and Korea. Neurointervention 


\section{Anesthetic Consideration for Neurointerventional Procedures}

2013;8:3-8

2. Lee YM, Hwang SM, Kim EH, Lee DG, Shim JH, Suh DC. Current status of neurointerventional activities in Korea. Neurointervention 2013;8:65-67

3. Jeong YG, Kim EH, Hwang SM, Lee GY, Kim JW, Choi YJ, et al. Outpatient (Same-day care) Neuroangiography and Neurointervention. Neurointervention 2012;7:17-22

4. Schaller SJ, Fink H. Sugammadex as a reversal agent for neuromuscular block: an evidence-based review. Core Evid 2013;8:57-67

5. Carmi U, Kramer MR, Zemtzov D, Rosengarten D, Fruchter O. Propofol safety in bronchoscopy: prospective randomized trial using transcutaneous carbon dioxide tension monitoring. Respiration 2011;82:515-521

6. Nelson DB, Barkun AN, Block KP, Burdick JS, Ginsberg GG, Greenwald DA, et al. Propofol use during gastrointestinal endoscopy. Gastrointest Endosc 2001;53:876-879

7. Smith AL, Wollman H. Cerebral blood flow and metabolism: effects of anesthetic drugs and techniques. Anesthesiology 1972;36:378-400

8. Tietjen CS, Hurn PD, Ulatowski JA, Kirsch JR. Treatment modalities for hypertensive patients with intracranial pathology: options and risks. Crit Care Med 1996;24:311-322

9. Strandgaard S, Olesen J, Skinhoj E, Lassen NA. Autoregulation of brain circulation in severe arterial hypertension. Br Med J 1973;1:507-510

10. Sokoloff L ea. Circulation and energy metabolism of the brain. Basic Neurochemistry 1989:565-566

11. Michenfelder JD. Cerebral blood flow and metabolism: In New York, Churchill Livingston. CilinicalNeuroanesthesia 1990:1-3

12. Pierce EC Jr, Lambertsen CJ, Deutsch S, Chase PE, Linde HW, Dripps RD, et al. Cerebral circulation and metabolism during thiopental anesthesia and hyper-ventilation in man. J Clin Invest 1962;41:1664-1671

13. Boarini DJ, Kassell NF, Coester HC, Butler M, Sokoll MD. Comparison of systemic and cerebrovascular effects of isoflurane and halothane. Neurosurgery 1984;15:400-409

14. Ginsberg B, Glass PS, Quill T, Shafron D, Ossey KD. Onset and duration of neuromuscular blockade following high-dose vecuronium administration. Anesthesiology 1989;71:201-205

15. Newell DW, Eskridge J, Mayberg M, Grady MS, Lewis D, Winn HR. Endovascular treatment of intracranial aneurysms and cerebral vasospasm. Clin Neurosurg 1992;39:348-360

16. Molyneux AJ, Kerr RS, Yu LM, Clarke M, Sneade M, Yarnold JA, et al. International subarachnoid aneurysm trial (ISAT) of neurosurgical clipping versus endovascular coiling in 2143 patients with ruptured intracranial aneurysms: a randomised comparison of effects on survival, dependency, seizures, rebleeding, subgroups, and aneurysm occlusion. Lancet 2005;366:809817

17. Broderick JP, Brott TG, Duldner JE, Tomsick T, Leach A. Initial and recurrent bleeding are the major causes of death following subarachnoid hemorrhage. Stroke 1994;25:1342-1347

18. van Rooij WJ, Sluzewski M, Beute GN. Brain AVM embolization with Onyx. AJNR Am J Neuroradiol 2007;28:172-177; discussion 178

19. Panagiotopoulos V, Gizewski E, Asgari S, Regel J, Forsting M, Wanke I. Embolization of intracranial arteriovenous malformations with ethylene-vinyl alcohol copolymer (Onyx). AJNR Am J Neuroradiol 2009;30:99-106

20. Shin SH, Kwon SC, Suh DC. Recent Update of Guidelines for Neurointerventional Procedures. Neurointervention 2013;8:68-72

21. Brott TG, Hobson RW, 2nd, Howard G, Roubin GS, Clark WM, Brooks W, et al. Stenting versus endarterectomy for treatment of carotid-artery stenosis. N Engl J Med 2010;363:11-23

22. Brott TG, Halperin JL, Abbara S, Bacharach JM, Barr JD, Bush RL, et al. 2011 ASA/ACCF/AHA/AANN/AANS/ACR/ASNR/ CNS/SAIP/SCAI/SIR/SNIS/SVM/SVS guideline on the management of patients with extracranial carotid and vertebral artery disease. Stroke 2011;42:e464-540

23. Suh DC, Kim JL, Kim EH, Kim JK, Shin JH, Hyun DH, et al. Carotid baroreceptor reaction after stenting in 2 locations of carotid bulb lesions of different embryologic origin. AJNR Am J Neuroradiol 2012;33:977-981

24. Park ST, Kim JK, Yoon KH, Park SO, Park SW, Kim JS, et al. Atherosclerotic carotid stenoses of apical versus body lesions in high-risk carotid stenting patients. AJNR Am J Neuroradiol 2010;31:1106-1112

25. Liu S, Jung JH, Kim SM, Lim HK, Kwon HJ, Kim JK, et al. Simultaneous bilateral carotid stenting in high-risk patients. AJNR Am J Neuroradiol 2010;31:1113-1117

26. van Mook WN, Rennenberg RJ, Schurink GW, van Oostenbrugge RJ, Mess WH, Hofman PA, et al. Cerebral hyperperfusion syndrome. Lancet Neurol 2005;4:877-888

27. Schroeder T, Sillesen H, Sorensen O, Engell HC. Cerebral hyperperfusion following carotid endarterectomy. J Neurosurg 1987;66:824-829

28. Sbarigia E, Speziale F, Giannoni MF, Colonna M, Panico MA, Fiorani P. Post-carotid endarterectomy hyperperfusion syndrome: preliminary observations for identifying at risk patients by transcranial Doppler sonography and the acetazolamide test. Eur $J$ Vasc Surg 1993;7:252-256

29. Murphy SW, Barrett BJ, Parfrey PS. Contrast nephropathy. J Am Soc Nephrol 2000;11:177-182

30. Au TH, Bruckner A, Mohiuddin SM, Hilleman DE. The Prevention of Contrast-Induced Nephropathy. Ann Pharmacother 2014

31. Zagler A, Azadpour M, Mercado C, Hennekens CH. N-acetylcysteine and contrast-induced nephropathy: a meta-analysis of 13 randomized trials. Am Heart J 2006;151:140-145

32. Bagshaw SM, Ghali WA. Theophylline for prevention of contrastinduced nephropathy: a systematic review and meta-analysis. Arch Intern Med 2005;165:1087-1093 